\title{
Macroeconomic Uncertainty and Macroeconomic Performance: Are they related?
}

\author{
Don Bredin \\ University College Dublin
}

\author{
Stilianos Fountas \\ University of Macedonia*
}

February 2004

\begin{abstract}
We use a very general multivariate GARCH-M model and G7 monthly data covering the 1957-2003 period to test for the impact of real and nominal macroeconomic uncertainty on inflation and output growth. Our evidence supports a number of important conclusions. First, in most countries output growth uncertainty is a positive determinant of the output growth rate. Second, there is mixed evidence regarding the effect of inflation uncertainty on inflation and output growth. Hence, uncertainty about the inflation rate is not necessarily detrimental to economic growth. Finally, there is mixed evidence on the effect of output uncertainty on inflation.
\end{abstract}

Keywords: Inflation, Output Uncertainty, Asymmetry, GARCH models

JEL Classification: C22, C51, C52, E0

*Address for correspondence: Stilianos Fountas, Department of Economics, University of Macedonia, 156 Egnatia St., Thessaloniki 540 06, Greece; e-mail: sfountas@uom.gr; tel: + 30-2310-891774; fax: +30-2310-891777. The authors would like to thank Olan Henry for helpful discussions on the methodology. Any errors are our own responsibility. 


\section{Introduction}

The issue of the welfare costs of inflation has been one of the most researched topics in macroeconomics both on the theoretical and empirical front. Considerable ambiguity surrounds the impact of the average rate of inflation on the rate of economic growth at the theoretical level. Furthermore, the impact of inflation on output growth may take place indirectly, via the inflation uncertainty channel. Friedman (1977) argues that a rise in the average rate of inflation leads to more uncertainty about the future rate of inflation, it distorts the effectiveness of the price mechanism in allocating resources efficiently, and thus it creates economic inefficiency and a lower growth rate of output. Moreover, inflation uncertainty by affecting interest rates also impacts on the intertemporal allocation of resources. Hence, a comprehensive empirical study that tests for the real effects of inflation should control for the impact of inflation uncertainty on output. The positive correlation between inflation and inflation uncertainty reported in empirical studies can also arise from a positive causal effect of inflation uncertainty on inflation. Cukierman and Meltzer (1986) provide a theoretical model that explains such a causal effect. In the presence of more inflation uncertainty, less conservative central bankers have an incentive to surprise the public and generate unanticipated inflation, hoping for output gains.

Early approaches to the testing of the relationship between inflation uncertainty on the one hand and inflation and output growth on the other hand, suffer from an important disadvantage. These studies did not distinguish between anticipated and unanticipated changes (the source of uncertainty) in inflation. By proxying inflation uncertainty by the moving standard deviation or variance of the inflation series, these studies measured inflation variability, not uncertainty. The development of Generalised Autoregressive Conditional Heteroskedasticity (GARCH) techniques allows the measurement of inflation uncertainty by the conditional variance of the inflation series and more accurate testing of the two parts of the Friedman hypothesis (e.g., Baillie et al., 1996, Grier and Perry, 1998, 2000; Fountas et al., 2004).

Output growth might be influenced by changes in real uncertainty (arising from the variability in output growth), in addition to changes in nominal or inflation uncertainty. Macroeconomic analysis before the 1980s treated the theories of the business cycle (and its variability) and economic growth independently. However, this assumption of independence between the variability of the business cycle and economic growth is questionable, as indicated by several theories (Mirman, 1971; Bernanke, 1983; Black, 1987; Pindyck, 1991). Empirical evidence has recently emerged that corroborates these theoretical findings (Caporale and McKiernan, 1996, 1998; Henry and Olekalns, 2001). This empirical evidence, though, is still scant and it only applies to data from the UK and the US. A robust set of evidence in support 
of the relationship between output growth and its variability would provide a solid ground for the development of macroeconomic models that consider such a relationship as a fundamental building block.

The above issues relating macroeconomic uncertainty and performance can be analysed in a univariate GARCH framework where the conditional variances of inflation and output growth are estimated independently from each other and then Granger causality tests are performed to examine the relationships between pairs of variables. Alternatively, a simultaneous approach can be adopted where a bivariate GARCH-in-mean (GARCH-M) model is estimated to provide estimates of the conditional variances and at the same time test for the impact of uncertainty on macroeconomic performance. This approach has been applied recently by Grier et al (2004) for the US economy. The authors test for and reject the diagonality and symmetry covariance restrictions of Grier and Perry (2000) and obtain quite different results.

Economic theory postulates certain causality relationships between nominal uncertainty, real uncertainty, the rate of inflation, and output growth. In total, including the relationships discussed above, twelve causality relationships exist among the above four variables. The empirical evidence on many of these relationships remains scant or nonexistent, as pertains, in particular, to international data in industrialized economies. The lack of a comprehensive study of the empirical relationships among the above four variables represents the motivation for the present study.

In this paper, the above issues are analysed empirically for the G7 with the use of a bivariate GARCH-M model. This model is similar to the one employed by Grier et al. (2004) and is applied to monthly data from 1957 to 2003. Our estimated model is used to generate the conditional variances of inflation and output growth as proxies of inflation and output growth uncertainty, respectively, and to test for the effect of real (output growth) and nominal (inflation) uncertainty on inflation and output growth. In total, four hypotheses are tested. The focus on a small set of hypotheses is chosen in order to concentrate our interest on a set of hypotheses that have considerable theoretical backing.

The paper is outlined as follows. Macroeconomic theory provides us with the predicted effects for these relationships discussed in Section 2. Section 3 summarises the empirical literature to date. Section 4 presents our econometric model and section 5 reports and discusses our results and relates them to some recent studies. Finally, Section 6 summarises our main conclusions and draws some policy implications. 


\section{Theory}

\subsection{The impact of inflation uncertainty on growth}

Friedman (1977) outlined an informal argument regarding the real effects of inflation. Friedman's point comes in two parts: In the first leg of the Friedman hypothesis, an increase in inflation may induce an erratic policy response by the monetary authority and therefore lead to more uncertainty about the future rate of inflation. In the second leg of the Friedman hypothesis, the increasing uncertainty about inflation distorts the effectiveness of the price mechanism in allocating resources efficiently, thus leading to negative output effects. Friedman's argument represents one of the few existing arguments on the rationalisation of the welfare effects of inflation.

The second part of Friedman's hypothesis predicts that increased inflation uncertainty would increase the observed rates of unanticipated inflation and hence will be associated with the costs of unanticipated inflation. ${ }^{1}$ Such costs arise from the effect of inflation uncertainty on both the intertemporal and intratemporal allocation of resources. Nominal uncertainty affects interest rates (the inflation premium) and hence all decisions relating to the intertemporal allocation of resources. In a world of nominal rigidities, inflation uncertainty also affects the real cost of the factors of production and the relative prices of final goods, and therefore, the intratemporal allocation of resources. The effect of inflation uncertainty on output has been addressed formally by Dotsey and Sarte (2000). In a cash-in-advance model that allows for precautionary savings and risk aversion, they show that more inflation uncertainty can have a positive output growth effect. According to the authors' argument, an increase in the variability of monetary growth, and therefore inflation, makes the return to money balances more uncertain and leads to a fall in the demand for real money balances and consumption. Hence, agents increase precautionary savings, and the pool of funds available to finance investment increases. This result is analogous to the literature's finding that fiscal policy uncertainty is conducive to growth by encouraging precautionary savings.

\subsection{The impact of inflation uncertainty on inflation}

The opposite direction of causality to that examined by Friedman in the inflation/inflation uncertainty relationship has also been addressed by the theoretical literature. This literature examines the impact of a change in inflation uncertainty on the average rate of inflation. Cukierman and Meltzer (1986) employ a Barro-Gordon model, where agents face uncertainty about

\footnotetext{
${ }^{1}$ This part draws on Huizinga (1993).
} 
the rate of monetary growth and therefore, inflation. In the presence of this uncertainty, the policymaker applies an expansionary monetary policy in order to surprise the agents and enjoy output gains. This argument implies a positive causal effect from inflation uncertainty to inflation and has been dubbed by Grier and Perry (1998) the Cukierman-Meltzer hypothesis. Holland (1995) has supplied a different argument based on the stabilisation motive of the monetary authority, the so-called "stabilising Fed hypothesis". He claims that, as inflation uncertainty rises due to increasing inflation, the monetary authority responds by contracting money supply growth, in order to eliminate inflation uncertainty and the associated negative welfare effects. Hence, Holland's argument supports the opposite sign in the causal relationship, i.e., a negative causal effect of inflation uncertainty on inflation. The theoretical ambiguity surrounding this causal relationship necessitates an empirical investigation of the sign of the effect.

\subsection{The effects of output uncertainty on inflation and output growth}

The effect of output growth uncertainty on inflation has been examined by Devereux (1989). Devereux (1989) extends the Barro-Gordon model by introducing wage indexation endogenously. He considers the impact of an exogenous increase in real (output) uncertainty on the degree of wage indexation and the optimal inflation rate delivered by the policymaker. He shows that more real uncertainty reduces the optimal amount of wage indexation and induces the policymaker to engineer more inflation surprises in order to obtain favourable real effects. The prediction of Devereux's theory regarding the positive causal effect of output uncertainty on the inflation rate is borne out also in a recent paper by Cukierman and Gerlach (2003). They show that, even if policymakers target the potential rate of unemployment, inflation bias a la Barro and Gordon obtains in the presence of more uncertainty about the level of output. This result hinges on the assumption that Central banks are more sensitive to employment below than above its normal level. From a theoretical point of view, it is possible for more output uncertainty to reduce inflation. Higher output uncertainty reduces inflation uncertainty ${ }^{2}$ and, therefore, the rate of inflation, according to the Cukierman-Meltzer hypothesis. Hence, the testable implication of these two effects combined is that more output growth uncertainty should lead to a lower rate of inflation.

The effect of output uncertainty on output growth has received considerable attention in the theoretical macroeconomic literature. However,

\footnotetext{
${ }^{2}$ The negative association between inflation and output variability is known in the literature as the Taylor effect.
} 
there is no consensus among macroeconomists on the direction of this effect. Macroeconomic theory offers three possible scenarios regarding the impact of output variability on output growth. First, there is the possibility of independence between output variability and growth. In other words, the determinants of the two variables are different from each other. For example, according to some business cycle models, output fluctuations around the natural rate are due to price misperceptions in response to monetary shocks. On the other hand, changes in the growth rate of output arise from real factors such as technology (Friedman, 1968).

The scenario of a negative association between output variability and average growth goes back to Keynes (1936), who argued that entrepreneurs, when estimating the return on their investment, take into consideration the fluctuations in economic activity. The larger the output fluctuations, the higher the perceived riskiness of investment projects and, hence, the lower the demand for investment and output growth. A similar result is obtained by the literature on sunspot equilibria (Woodford, 1990). According to Bernanke (1983) and Pindyck (1991), the negative relationship between output volatility and growth arises from investment irreversibilities at the firm level. Ramey and Ramey (1991) show that in the presence of commitment to technology in advance, higher output volatility can lead to suboptimal ex post output levels by firms (due to uncertainty-induced planning errors) and hence, lower mean output and growth.

Finally, the positive impact of output variability on growth can be justified by the following two economic theories: First, more income variability (uncertainty) would lead to a higher savings rate (Sandmo, 1970) for precautionary reasons, and hence, according to Solow's (1956) neoclassical growth theory, a higher equilibrium rate of economic growth. This argument has been advanced by Mirman (1971). The alternative explanation is due to Black (1987) and is based on the hypothesis that investments in riskier technologies will be pursued only if the expected return on these investments (average rate of output growth) is large enough to compensate for the extra risk. As real investment takes time to materialize, such an effect would be more likely to obtain in empirical studies utilizing low-frequency data. All the theories presented in section 2 are summarised in the following Table. 


\begin{tabular}{|c|c|}
\hline Testable hypotheses-Theories & $\begin{array}{l}\text { Sign of } \\
\text { the effect }\end{array}$ \\
\hline \multicolumn{2}{|l|}{ 1) Inflation uncertainty Granger-causes inflation. } \\
\hline Cukierman-Meltzer (1986) & + \\
\hline Holland (1995) & - \\
\hline \multicolumn{2}{|c|}{ 2) Inflation uncertainty Granger-causes output growth. } \\
\hline Friedman (1977) & - \\
\hline Dotsey and Sarte (2000) & + \\
\hline \multicolumn{2}{|l|}{ 3) Output uncertainty Granger-causes inflation. } \\
\hline Devereux (1989), Cukierman-Gerlach (2003) & + \\
\hline Taylor effect and Cukierman-Meltzer (1986) & - \\
\hline \multicolumn{2}{|c|}{ 4) Output uncertainty Granger-causes output growth. } \\
\hline Business cycle models & zero \\
\hline $\begin{array}{l}\text { Keynes (1936), Bernanke (1983), Woodford (1990), } \\
\text { Pindyck (1991), Ramey and Ramey (1991) }\end{array}$ & - \\
\hline Mirman (1971), Black (1987) & + \\
\hline
\end{tabular}

\section{The empirical evidence}

Early empirical studies on the relationship between inflation and its uncertainty used the variance (or standard deviation) as a measure of uncertainty and hence measured inflation variability as opposed to uncertainty. Following the development of the ARCH approach by Engle (1982), several studies measured inflation uncertainty using the conditional variance of the inflation process. The majority of these studies tests for the impact of inflation on inflation uncertainty. The evidence on the impact of inflation uncertainty on growth is more limited and is summarised in Holland (1993). GARCH studies of this issue that represent a more accurate test of the hypothesis that inflation uncertainty has negative welfare effects are mostly based on US data (e.g., Coulson and Robins, 1985; Jansen, 1989; Grier and Perry, 2000, Grier et al., 2004). Exceptions are the studies of Fountas and Karanasos (2004) and Fountas et al (2004) which use data on the G7 and six European countries, respectively. The evidence is rather mixed. Grier and Perry (2000) and Grier et al. (2004) find evidence for a negative effect. In contrast, Coulson and Robins (1985) and Jansen (1989) find evidence for a positive and zero effect, respectively. Fountas et al (2004) and Fountas and Karanasos (2004) find mixed evidence using a two-step approach that combines the estimation of a GARCH model with the implementation of Granger-causality tests.

The causal impact of inflation uncertainty on inflation is tested empirically using the GARCH approach in Baillie et al (1996), Grier and Perry (1998, 2000), Grier et al. (2004) and Fountas et al (2004). Grier and Perry 
(2000) and Grier et al. (2004) use only US data, whereas the rest of the studies use international data. In general, the evidence is mixed. Baillie et al (1996) find evidence supporting the link between the two variables for the UK and some high-inflation countries, whereas Grier and Perry (1998) in their G7 study find evidence in favour of the Cukierman-Meltzer hypothesis for some countries and in favour of the Holland hypothesis for other countries. Fountas et al. (2004) also obtain mixed evidence. Finally, Grier and Perry (2000) and Grier et al. (2004) find evidence for a zero and negative effect of inflation uncertainty on inflation in the US, respectively.

The empirical evidence to date on the association between output variability and output growth is mixed. Early studies employed cross section (Kormendi and Meguire, 1985) or pooled data (Grier and Tullock, 1989) and find evidence for a positive association. Ramey and Ramey (1995) use a panel of 92 countries and a sample of OECD countries (for the 1960-1985 period) and find strong evidence that countries with higher output variability have lower growth. A similar result is obtained by Zarnowitz and Moore (1986), who divide the 1903-1981 period into 6 subperiods and compare high and low growth periods in terms of output growth variability (measured by the standard deviation of the annual growth rate in real GNP). Empirical evidence on the causal effect of output growth uncertainty (as opposed to variability) on output growth has appeared only recently. Caporale and McKiernan $(1996,1998)$ obtain evidence of a positive causal effect using UK and US data, respectively, supporting, among others, the Black hypothesis. Speight (1999) finds no relationship between output growth uncertainty and output growth in the UK and Henry and Olekalns (2001) find evidence of a negative effect in the US. Grier et al. (2004) finds US evidence for the Black hypothesis. Fountas and Karanasos (2004) obtain significant evidence for the same hypothesis in most of the G7. Finally, the available empirical evidence on the Devereux hypothesis is rather limited. Grier and Perry (2000) and Grier et al. (2004) find no evidence using US data and Fountas and Karanasos (2004) find supportive evidence for Italy and the UK.

\section{Econometric Methodology}

In equation 1 below we show the approach used to model both output growth $\left(y_{t}\right)$ and inflation $\left(\pi_{t}\right)$ simultaneously. A VARMA (vector autoregressive moving average) GARCH-M model is adopted (see Grier et al., 2004). This approach simultaneously estimates equations for both inflation and output growth and takes into account the conditional variances as explanatory variables. The standard information criteria will be used to test the lag length for both $p$ and $q$. 


$$
\begin{gathered}
Y_{t}=\mu+\sum_{i=1}^{p} \Gamma_{i} Y_{t-i}+\Psi \sqrt{h_{t}}+\sum_{j=1}^{q} \Theta_{j} \epsilon_{t-j}+\epsilon_{t} \quad \text { where } \epsilon_{t} \sim\left(0, H_{t}\right) \\
H_{t}=\left(\begin{array}{cc}
h_{y, t} & h_{y \pi, t} \\
h_{y \pi, t} & h_{\pi, t}
\end{array}\right) \\
\text { where } \quad Y_{t}=\left(\begin{array}{c}
y_{t} \\
\pi_{t}
\end{array}\right) ; \epsilon_{t}=\left(\begin{array}{c}
\epsilon_{y, t} \\
\epsilon_{\pi, t}
\end{array}\right) ; \sqrt{h_{t}}=\left(\begin{array}{c}
\sqrt{h_{y, t}} \\
\sqrt{h_{\pi, t}}
\end{array}\right) ; \mu=\left(\begin{array}{c}
\mu_{y} \\
\mu_{\pi}
\end{array}\right) \\
\Gamma_{i}=\left(\begin{array}{cc}
\Gamma_{11}^{(i)} & \Gamma_{12}^{(i)} \\
\Gamma_{21}^{(i)} & \Gamma_{22}^{(i)}
\end{array}\right) ; \Psi=\left(\begin{array}{cc}
\Psi_{11} & \Psi_{12} \\
\Psi_{21} & \Psi_{22}
\end{array}\right) ; \Theta_{j}=\left(\begin{array}{cc}
\Theta_{11}^{(j)} & \Theta_{12}^{(j)} \\
\Theta_{21}^{(j)} & \Theta_{22}^{(j)}
\end{array}\right)
\end{gathered}
$$

where $\epsilon_{t} \mid \Omega_{t} \sim\left(0, H_{t}\right)$, and $\Omega_{t}$ is the information set available at time t. The model will be estimated using maximum likelihood subject to $H_{t}$, the conditional covariance matrix, being positive definite.

The GARCH-M approach is adopted in order to take account of the possible influence of uncertainty about output growth and inflation on average growth and inflation. The effects of uncertainty on inflation and output growth are captured by the elements of matrix $\Psi . \quad \Psi_{11}$ and $\Psi_{21}$ test for the impact of output growth uncertainty on output growth and the inflation rate, respectively. Positive and significant values for these two coefficients would lend support to the Black and Devereux hypotheses, respectively. $\Psi_{12}$ and $\Psi_{22}$ test for the impact of inflation uncertainty on output growth and the inflation rate, respectively. Respective (significant) negative and positive values for these two coefficients would lend support to the Friedman and Cukierman-Meltzer hypotheses, respectively.

An important distinction between our model and the vast majority of previous studies is that our model takes account of any possible nondiagonality and asymmetries in the covariance structures. An exception is the work of Grier et al. (2004) who test for, rather than assume, diagonality and symmetry using US data. The conditional covariance can be written as,

$$
H_{t}=C_{0}^{*^{\prime}} C_{0}^{*}+B_{11}^{*^{\prime}} H_{t-1} B_{11}^{*}+A_{11}^{*^{\prime}} \epsilon_{t-1} \epsilon_{t-1}^{\prime} A_{11}^{*}+D_{11}^{*^{\prime}} \xi_{t-1} \xi_{t-1}^{\prime} D_{11}^{*}
$$

where $\quad C_{0}^{*}=\left(\begin{array}{cc}c_{11}^{*} & c_{12}^{*} \\ 0 & c_{22}^{*}\end{array}\right) ; B_{11}^{*}=\left(\begin{array}{cc}\beta_{11}^{*} & \beta_{12}^{*} \\ \beta_{21}^{*} & \beta_{22}^{*}\end{array}\right) ; A_{11}^{*}=\left(\begin{array}{cc}\alpha_{11}^{*} & \alpha_{12}^{*} \\ \alpha_{21}^{*} & \alpha_{22}^{*}\end{array}\right)$; 


$$
D_{11}^{*}=\left(\begin{array}{ll}
\delta_{11}^{*} & \delta_{12}^{*} \\
\delta_{21}^{*} & \delta_{22}^{*}
\end{array}\right) ; \xi_{t}^{2}=\left(\begin{array}{c}
\xi_{y, t}^{2} \\
\xi_{\pi, t}^{2}
\end{array}\right)
$$

Does the volatility in one series spillover into the volatility of another series? In equation 2, a diagonal covariance process requires that the off diagonal elements of the $A_{11}^{*}, B_{11}^{*}$ and $D_{11}^{*}$ matrices be jointly insignificant. Second, does bad news lead to greater volatility than good news? Specifically, bad news in terms of inflation (output growth) is taken as higher (lower) than expected inflation (output growth) will have a positive (negative) residual. We set the model up in such a way that $\xi_{\pi, t}$ be the $\max \left(\epsilon_{\pi, t}, 0\right)$ which is the positive innovations regarding inflation or bad news. The $\xi_{y, t}$ is the $\min \left(\epsilon_{y, t}, 0\right)$ which is the negative innovations regarding output growth or bad news. If there was no asymmetry present, then the coefficient matrix $D_{11}^{*}$ would not be statistically significant and equation 2 would be the symmetric $B E K K$ model (Engle \& Kroner, 1995).

\section{Data and results}

\subsection{Data}

We use monthly data on the Industrial Production Index (IPI) and a price index (Consumer Price Index, CPI or Producer Price Index, PPI) as proxies for output and the price level, respectively. The data refer to the G7, cover the period 1957-2003 and are taken from the International Financial Statistics (IMF). The precise sample period and measure of the price index in each country is given in Table 1 . We measure inflation by the annualized monthly difference of the logarithm of the price index PI $\left[\pi_{t}=\log \left(\frac{\mathrm{PI}_{t}}{\mathrm{PI}_{t-1}}\right) \times 1200\right]$ and real output growth by the annualized monthly difference in the logarithm of the IPI $\left[y_{t}=\log \left(\frac{\mathrm{IPI}_{t}}{\mathrm{IPI}_{t-1}}\right) \times 1200\right]$. Summary statistics on inflation and output growth are given in Table 1 . We first test for the stationarity properties of our data using the Augmented DickeyFuller (ADF) and Phillips-Perron (PP) tests. The results of these tests indicate that we can treat the inflation rate and the growth rate of industrial production in each country as stationary processes. ${ }^{3}$

\section{$5.2 \quad$ US results}

We estimate the model of equations (1) and (2) using the quasi-maximum likelihood estimation proposed by Bollerslev and Wooldridge (1992). Table

\footnotetext{
${ }^{3}$ Results are available from the authors upon request.
} 
2 reports the estimated results of the multivariate GARCH-M model for the US. We report the inflation and output growth equations, some residual diagnostics and the conditional variance equations. On the basis of the information criteria, we have set $\mathrm{p}$ and $\mathrm{q}$ equal to one and six, respectively.

The reported estimated coefficients of the $A_{11}^{*}, B_{11}^{*}$ and $D_{11}^{*}$ matrices are of special significance. First, the statistical significance of the $A_{11}^{*}, B_{11}^{*}$ and $D_{11}^{*}$ matrices provides evidence for heteroskedastic conditional variance. The results of Table 2 indicate that these three matrices are jointly significant at the $1 \%$ level. Second, the joint statistical significance of the off-diagonal elements of the same three matrices indicates that lagged conditional variances and lagged squared innovations in inflation (output growth), tend to affect the conditional variance of output growth (inflation). More specifically, the joint significance of the $A_{11}^{*}$ and $D_{11}^{*}$ matrices at $1 \%$ implies that shocks to inflation or output growth tend to influence with a lag uncertainty about the other macroeconomic variable, i.e., output growth or inflation. Third, the joint significance of the elements of the $D_{11}^{*}$ matrix at $1 \%$ leads us to conclude that the covariance process is asymmetric. In particular, the sign of $d_{11}^{*}$ shows that negative output growth shocks raise uncertainty about output growth more than positive shocks do. The significance of $d_{22}^{*}$ shows that positive inflation shocks raise uncertainty about inflation more than negative shocks do. In other words, both inflation and output growth are characterised by own variance asymmetry.

We perform a number of tests to ensuse the model fits the data well. First, the values of the Ljung-Box statistics indicate the absence of serial correlation up to 4 th and 12 th order in the standardised and squared standardised residuals in both the inflation and output growth equations. Second, we test for the model's predictions that $\mathrm{E}\left(\varepsilon_{i t}^{2}\right)=h_{i, t}, i=y, \pi$, and $\mathrm{E}\left(\varepsilon_{y, t} \varepsilon_{\pi, t}\right)=h_{y \pi, t}$. These moment-based test results reported in Table 2 show that the above conditions cannot be rejected at $5 \%$.

The four economic theories presented in section 2 regarding the impact of macroeconomic uncertainty on macroeconomic performance, namely inflation and output growth, can be tested by the sign and significance of the elements of matrix $\Psi$. Our results in Table 2 indicate that the coefficients $\Psi_{11}$ and $\Psi_{12}$ are statistically significant at $1 \%$ and the coefficients $\Psi_{21}$ and $\Psi_{22}$ are statistically insignificant at any conventional levels of significance. The positive and significant value of $\Psi_{11}$ implies that output growth uncertainty proxied by the conditional variance is a positive determinant of output growth, thus supporting the Black hypothesis. The negative and significant value of $\Psi_{12}$ provides strong support to the Friedman hypothesis that inflation uncertainty is detrimental to output growth, thus corroborating the belief that inflation is costly and its effect on growth works via changes in inflation uncertainty. The insignificance of $\Psi_{21}$ shows a lack 
of support for the Devereux hypothesis and the insignificance of $\Psi_{22}$ indicates that inflation uncertainty has no effect on the rate of inflation, thus contradicting both the Cukierman-Meltzer and Holland hypotheses.

\subsection{Results for the other G7 Countries}

We estimate multivariate GARCH-M models allowing for asymmetries for the rest of the G7 following the approach adopted for the US. For each country we test for various nested specifications which include: a diagonal VARMA for the inflation and output equations, a diagonal GARCH specification, homoskedastic conditional variances, lack of GARCH-M effects, and lack of asymmetries in the conditional variances. According to the results reported in Table 3, all five nested specifications are rejected by the data at $1 \%$ for all countries except Japan where we find no evidence for asymmetries.

Next we focus our attention on the statistical significance and signs of the elements of matrix $\Psi$ in order to test for the four economic hypotheses presented in section 2. The estimates of $\Psi$ and the associated standard errors are reported in Table 4. Our results on these hypotheses are summarised as follows. First, we obtain support for the Black hypothesis in Canada, Germany and the UK as output uncertainty affects output growth positively. In France and Italy, output uncertainty affects growth negatively corroborating Bernanke (1983). Only in Japan we find evidence for independence between output uncertainty and growth. Second, regarding the impact of inflation uncertainty on growth, the evidence is mixed. We obtain evidence for a negative effect only in the UK. In contrast in three countries, Canada, France and Italy we find that inflation uncertainty boosts output growth supporting Dotsey and Sarte (2000). In the rest of the countries, Germany and Japan, uncertainty about inflation does not impact on growth. Third, inflation uncertainty affects inflation positively in four countries, Canada, France, Germany and Italy, providing significant support to the CukiermanMeltzer hypothesis. For Japan and the UK there is no significant effect. Finally, we find evidence for the Devereux hypothesis (positive effect of output uncertainty on inflation) in France, Japan and the UK. In the rest of the countries our results provide no support to the hypothesis as the effect is either negative (Canada and Italy) or zero (Germany).

\subsection{Discussion of results and related recent literature}

The G7 results presented above are interesting and carry noteworthy implications for macroeconomic modeling and policymaking. Our evidence 
that in six of the seven countries output incertainty and output growth are related suggests that macro theorists should incorporate the analysis of output uncertainty into growth models, as the two seem to be interrelated. Moreover, in most countries of our sample we find support for the Black hypothesis implying that output uncertainty is a positive determinant of output growth. The country-specific evidence on the Cukierman-Meltzer hypothesis is anticipated given that national central banks adjust their rate of money growth differently to inflation uncertainty depending on their relative preference towards inflation and output stabilisation.

Our mixed evidence on the hypothesis advanced by Friedman that uncertainty about inflation is detrimental to growth squares with the lack of a consensus that has been established by the broad empirical research on this matter. This literature, summarised in Holland (1993), reports mixed results that are sensitive to factors such as the measure of inflation uncertainty, the chosen econometric methodology, the countries examined, and the sample period. Regarding the causal effect of output uncertainty on the inflation rate, our time series evidence is rather mixed. It should be emphasised that the available empirical studies on the Devereux hypothesis are rather limited and include mostly US data. To the best of our knowledge the present study and Fountas and Karanasos (2004) are the only exceptions.

The most closely related studies to the present work are Grier and Perry (2000), Grier et al. (2004) and Fountas and Karanasos (2004). There are several differences among these studies. Grier and Perry (2000) and Grier et al. (2004) use US data and the simultaneous approach, whereas Fountas and Karanasos (2004) use G7 data and the two-step approach. Grier and Perry (2000) use monthly US data for 1948-1996. Out of the four hypotheses tested the authors find support only for the Friedman hypothesis. Our US results differ in one respect: we also find support for the Black hypothesis.

Grier et al. (2004) use monthly US data for the 1947-2000 period. Our US evidence based on a more recent sample differs from this study only in terms of the effect of inflation uncertainty on inflation. We find evidence for a zero impact, whereas Grier et al. (2004) obtain evidence for the Holland hypothesis. Our evidence in the rest of the G7 countries can be compared with the findings of Fountas and Karanasos (2004) who use data for the 1957-2000 period. A comparison of the results of the two studies shows similarities and differences. Both studies conclude that, first, there is strong evidence for the Black hypothesis in most countries, and second, there is mixed evidence on the Friedman and Devereux hypotheses. An important difference in the results between the two studies is that Fountas and Karanasos (2004) find some evidence for the Holland hypothesis but the present study finds no such evidence for any of the G7. 


\section{Conclusions}

We have used a multivariate GARCH-M model that allows for asymmetries in the G7 to examine the effects of real and nominal uncertainty on average inflation and output growth. This methodology is quite general as it nests other simpler GARCH models and allows us to test for four economic theories associated with the Friedman, Cukierman-Meltzer, Black, and Devereux hypotheses. Our simultaneous approach that proxies uncertainty by the conditional variance of unanticipated shocks to the time series of inflation and output growth leads to a number of important conclusions. First, the uncertainty associated with the rate of inflation seems to have mixed effects on output growth. In other words, Friedman's belief that inflation uncertainty can be detrimental to the economy's real sector receives only some support in our study. This finding is in line with various studies that have documented a lack of consensus on the output effects of nominal uncertainty. Second, we obtain mixed evidence in favour of the CukiermanMeltzer hypothesis. Thus, as expected, countries are anticipated to react differently to a change in the degree of uncertainty surrounding the inflation rate. Third, we find that in most countries output growth uncertainty is a positive determinant of the growth rate as predicted by Black (1987), whereas in some countries the effect is negative. This result has important implications for the development of macroeconomic theory as it provides the motivation for the simultaneous analysis of economic growth and business cycle variability in macroeconomic modelling. Finally, some support for the positive contribution of output uncertainty to inflation, i.e., the Devereux hypothesis, obtains. Our consideration of a very recent sample period and our comparison with other relevant studies, notably Grier and Perry (2000), Grier et al. (2004) and Fountas and Karanasos (2004), points towards the sensitivity of the results to the methodological approach and the time period examined. Therefore, our empirical study highlights the need for further work on the causal relationships between inflation, output growth, and real and nominal uncertainty. 


\section{References}

[1] Baillie, R., Chung, C., Tieslau, M., 1996. "Analyzing inflation by the fractionally integrated ARFIMA-GARCH model", Journal of Applied Econometrics 11, 23-40.

[2] Bernanke, B., 1983. "Irreversibility, uncertainty, and cyclical investment", Quarterly Journal of Economics 98, 85-106.

[3] Black, F., 1987. Business Cycles and Equilibrium, New York: Basil Blackwell.

[4] Bollerslev, T., Wooldridge, J. M., 1992. "Quasi-maximum likelihood estimation and inference in dynamic models with time varying covariances", Econometric Reviews, 11, 143-172.

[5] Caporale, T., McKiernan, B., 1996. "The relationship between output variability and growth: evidence from post war UK data", Scottish Journal of Political Economy, 43, 229-236.

[6] Caporale, T., McKiernan, B., 1998. "The Fischer Black hypothesis: some time-series evidence“, Southern Economic Journal, 64, 765-771.

[7] Coulson, E., Robins, R., 1985. "Aggregate economic activity and the variance of inflation: another look", Economics Letters, 71-75.

[8] Cukierman, A., Gerlach, S., 2003. "The inflation bias revisited: theory and some international evidence“, The Manchester School 71, 541-565.

[9] Cukierman, A., Meltzer, A., 1986. "A theory of ambiguity, credibility, and inflation under discretion and asymmetric information", Econometrica 54, 1099-1128.

[10] Devereux, M., 1989. "A positive theory of inflation and inflation variance", Economic Inquiry 27, 105-116.

[11] Dotsey, M., Sarte, P., 2000. "Inflation uncertainty and growth in a cash-in-advance economy “, Journal of Monetary Economics 45, 631655.

[12] Engle, R. F., 1982. "Autoregressive conditional heteroskedasticity with estimates of the variance of UK inflation ", Econometrica 50, 987-1008.

[13] Engle, R. F., Kroner, K., 1995. "Multivariate Simultaneous generalised ARCH“, Econometric Theory 11, 122-150.

[14] Fountas, S., Ioannidis, A., Karanasos, M., 2004. "Inflation, inflation uncertainty, and a common European monetary policy ", Manchester School 72, forthcoming. 
[15] Fountas, S., Karanasos, 2004. "Inflation, output growth, and nominal and real uncertainty: empirical evidence for the G7", Unpublished manuscript.

[16] Friedman, M., 1968. "The role of monetary policy", American Economic Review 58, 1-17.

[17] Friedman, M., 1977. "Nobel lecture: Inflation and Unemployment", Journal of Political Economy 85, 451-472.

[18] Grier, K., Henry, O., Olekalns, N., Shields, K., 2004. "The asymmetric effects of uncertainty on inflation and output growth", Journal of Applied Econometrics, forthcoming.

[19] Grier, K., Perry, M., 1998. "On inflation and inflation uncertainty in the G7 countries“, Journal of International Money and Finance 17, 671-689.

[20] Grier, K., Perry, M., 2000. "The effects of real and nominal uncertainty on inflation and output growth: Some GARCH-M evidence“, Journal of Applied Econometrics 15, 45-58.

[21] Grier, K., Tullock, G., 1989. "An empirical analysis of cross-national economic growth, 1951-1980“, Journal of Monetary Economics 24, 259276.

[22] Henry, O., Olekalns, N., 2001. "The effect of recessions on the relationship between output variability and growth", Southern Economic Journal 68, 683-692.

[23] Holland, S., 1993. "Comment on inflation regimes and the sources of inflation uncertainty", Journal of Money, Credit, and Banking 25, 514-520.

[24] Holland, S., 1995. "Inflation and uncertainty: Tests for temporal ordering “, Journal of Money, Credit, and Banking 27, 827-837.

[25] Huizinga, J., 1993. "Inflation uncertainty, relative price uncertainty, and investment in US manufacturing ", Journal of Money, Credit, and Banking 25, 521-549.

[26] Jansen, D., 1989. "Does inflation uncertainty affect output growth? Further evidence“, Federal Reserve Bank of St. Louis Review, 43-54.

[27] Keynes, J. M., 1936. The General Theory of employment, interest, and money, London: Macmillan. 
[28] Kormendi, R., Meguire, P., 1985. "Macroeconomic determinants of growth: cross-country evidence“, Journal of Monetary Economics 16, 141-163.

[29] Mirman, L., 1971. "Uncertainty and optimal consumption decisions", Econometrica 39, 179-185.

[30] Pindyck, R., 1991. "Irreversibility, uncertainty, and investment", Journal of Economic Literature 29, 1110-1148.

[31] Ramey, G., Ramey, V., 1991. "Technology commitment and the cost of economic fluctuations", NBER Working Paper No. 3755.

[32] Ramey, G., Ramey, V., 1995. "Cross-country evidence on the link between volatility and growth", American Economic Review 85, 11381151.

[33] Sandmo, A., 1970. "The effect of uncertainty on saving", Review of Economic Studies 37, 312-320.

[34] Solow, R., 1956. "A contribution to the theory of economic growth", Quarterly Journal of Economics 70, 65-94.

[35] Speight, A.,1999. "UK output variability and growth: some further evidence“, Scottish Journal of Political Economy 46, 175-184.

[36] Woodford, M., 1990. "Learning to believe in sunspots", Econometrica 58, 277-307.

[37] Zarnowitz, V., Moore, G., 1986. "Major changes in cyclical behaviour", in R. Gordon (ed.): The American Business Cycle, University of Chicago Press. 
Table 1: Summary Statistics

\begin{tabular}{cccccc}
\hline \hline Variable & Sample & Mean & Min & Max & Std Error \\
\hline Inflation & & & & & \\
\hline US & $(1957 M 1-2003 M 5)$ & 3.20 & -39.69 & 67.76 & 8.42 \\
UK & $(1957 M 1-2003 M 4)$ & 4.92 & -188.87 & 46.80 & 10.83 \\
Japan & $(1957 M 1-2003 M 5)$ & 3.76 & -18.75 & 49.20 & 8.80 \\
Italy & $(1957 M 1-2001 M 5)$ & 6.87 & -10.33 & 37.12 & 6.87 \\
Germany & $(1957 M 1-2003 M 4)$ & 2.07 & -18.69 & 34.14 & 4.60 \\
France & $(1957 M 1-2003 M 4)$ & 5.22 & -10.27 & 39.40 & 5.26 \\
Canada & $(1957 M 1-2003 M 4)$ & 4.21 & -10.31 & 31.12 & 4.71 \\
\hline Industrial Production & & & & & \\
\hline US & $(1957 M 1-2003 M 5)$ & 2.94 & -44.20 & 71.96 & 10.41 \\
UK & $(1957 M 1-2003 M 4)$ & 1.62 & -99.05 & 11.53 & 17.32 \\
Japan & $(1957 M 1-2003 M 5)$ & 5.30 & -52.47 & 64.65 & 17.83 \\
Italy & $(1957 M 1-2001 M 5)$ & 3.65 & -172.72 & 117.41 & 28.43 \\
Germany & $(1957 M 1-2003 M 4)$ & 1.14 & -831.50 & 172.05 & 44.72 \\
France & $(1957 M 1-2003 M 4)$ & 2.68 & -452.18 & 271.83 & 31.10 \\
Canada & $(1957 M 1-2003 M 4)$ & 3.33 & -75.95 & 85.24 & 15.48 \\
\hline \hline
\end{tabular}

All data is taken from the International Financial Statistics (IFS) of the IMF. Producer price index is used for Germany, UK and the US. Consumer Price Index is used for France, Italy, Japan, and Canada. 
Table 2: Multivariate GARCH-M Model with Asymmetry Conditional Mean Equations

$$
\begin{aligned}
& Y_{t}=\mu+\sum_{i=1}^{p} \Gamma_{i} Y_{t-i}+\Psi \sqrt{h_{t}}+\sum_{j=1}^{q} \Theta_{j} \epsilon_{t-j}+\epsilon_{t} \quad \text { where } \epsilon_{t} \sim\left(0, H_{t}\right) \\
& \text { where } \quad Y_{t}=\left(\begin{array}{c}
y_{t} \\
\pi_{t}
\end{array}\right) ; \epsilon_{t}=\left(\begin{array}{c}
\epsilon_{y, t} \\
\epsilon_{\pi, t}
\end{array}\right) ; \sqrt{h_{t}}=\left(\begin{array}{c}
\sqrt{h_{y, t}} \\
\sqrt{h_{\pi, t}}
\end{array}\right) ; \mu=\left(\begin{array}{c}
\mu_{y} \\
\mu_{\pi}
\end{array}\right) \\
& \Gamma_{i}=\left(\begin{array}{cc}
\Gamma_{11}^{(i)} & \Gamma_{12}^{(i)} \\
\Gamma_{21}^{(i)} & \Gamma_{22}^{(i)}
\end{array}\right) ; \Psi=\left(\begin{array}{ll}
\Psi_{11} & \Psi_{12} \\
\Psi_{21} & \Psi_{22}
\end{array}\right) ; \Theta_{j}=\left(\begin{array}{cc}
\Theta_{11}^{(j)} & \Theta_{12}^{(j)} \\
\Theta_{21}^{(j)} & \Theta_{22}^{(j)}
\end{array}\right) \\
& \mu=\left(\begin{array}{c}
0.28 \\
(0.34) \\
0.32 \\
(0.17)
\end{array}\right) \Gamma_{1}=\left(\begin{array}{cc}
0.86 & -0.05 \\
(0.05) & (0.05) \\
-0.04 & 0.90 \\
(0.04) & (0.03)
\end{array}\right) \Psi=\left(\begin{array}{cc}
0.11 & -0.09 \\
(0.03) & (0.03) \\
0.02 & -0.01 \\
(0.03) & (0.04)
\end{array}\right) \\
& \Theta_{1}=\left(\begin{array}{cc}
-0.66 & 0.07 \\
(0.06) & (0.06) \\
0.06 & -0.61 \\
(0.05) & (0.06)
\end{array}\right) \Theta_{2}=\left(\begin{array}{cc}
0.02 & 0.04 \\
(0.03) & (0.03) \\
0.03 & -0.17 \\
(0.01) & (0.03)
\end{array}\right) \Theta_{3}=\left(\begin{array}{cc}
0.01 & -0.07 \\
(0.02) & (0.03) \\
-0.02 & 0.01 \\
(0.01) & (0.03)
\end{array}\right) \\
& \Theta_{4}=\left(\begin{array}{cc}
0.03 & -0.05 \\
(0.03) & (0.03) \\
0.01 & -0.06 \\
(0.01) & (0.03)
\end{array}\right) \Theta_{5}=\left(\begin{array}{cc}
-0.12 & 0.05 \\
(0.03) & (0.04) \\
0.02 & -0.01 \\
(0.01) & (0.02)
\end{array}\right) \Theta_{6}=\left(\begin{array}{cc}
0.05 & -0.02 \\
(0.03) & (0.03) \\
-0.01 & 0.11 \\
(0.01) & (0.02)
\end{array}\right)
\end{aligned}
$$

Residual Diagnostics

\begin{tabular}{ccccccc}
\hline \hline & Mean & Standard Error & $Q(4)$ & $Q^{2}(4)$ & $Q(12)$ & $Q^{2}(12)$ \\
\hline$\epsilon_{1, t}$ & -0.01 & 0.99 & 1.24 & 8.34 & 7.34 & 10.71 \\
& & & {$[0.87]$} & {$[0.10]$} & {$[0.83]$} & {$[0.55]$} \\
$\epsilon_{2, t}$ & \multirow{2}{*}{0.01} & \multirow{2}{*}{1.03} & 0.73 & 2.18 & 16.48 & 12.14 \\
& & & {$[0.95]$} & {$[0.70]$} & {$[0.17]$} & {$[0.43]$} \\
\hline
\end{tabular}


Moment Based Test

\begin{tabular}{ccc}
\hline \hline$E\left(\epsilon_{y, t}^{2}\right)=h_{y, t}$ & $E\left(\epsilon_{\pi, t}^{2}\right)=h_{\pi, t}$ & $E\left(\epsilon_{y, t}, \epsilon_{\pi, t}\right)=h_{y \pi, t}$ \\
0.99 & 0.57 & 2.02 \\
{$[0.31]$} & {$[0.45]$} & {$[0.16]$} \\
\hline \hline
\end{tabular}

Conditional Variance Covariance Equations

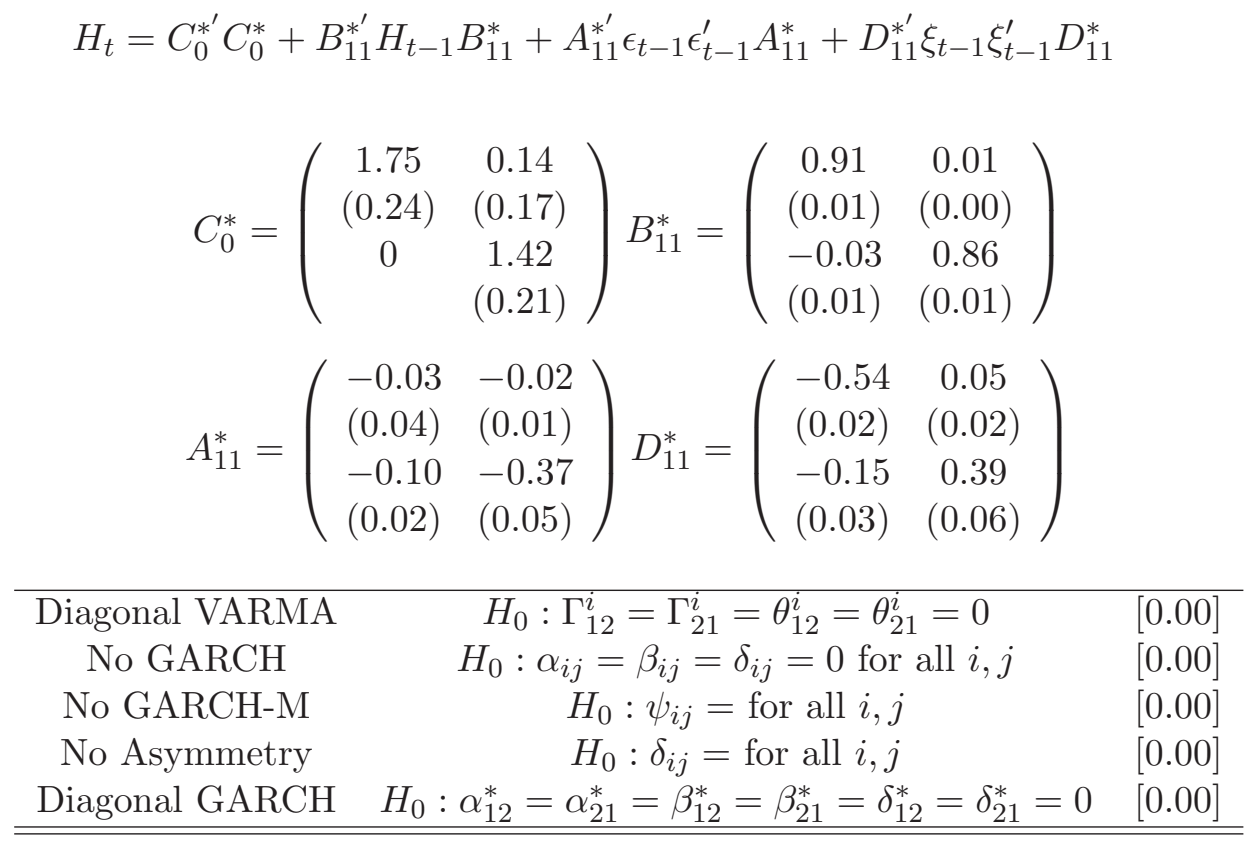

Note: The standard errors are in brackets and marginal significance levels are in squared brackets. $Q(p)$ and $Q^{2}(p)$ are the Ljung Box test statistic for $p^{\text {th }}$ order serial correlation for the standardised residuals and squared residuals, respectively. 
Table 3: Specification Tests for the remainder of the G7

\begin{tabular}{|c|c|c|c|}
\hline \multirow[t]{5}{*}{ Canada } & "Diagonal VARMA & $H_{0}: \Gamma_{12}^{i}=\Gamma_{21}^{i}=\theta_{12}^{i}=\theta_{21}^{i}=0$ & {$[0.00]$} \\
\hline & No GARCH & $H_{0}: \alpha_{i j}=\beta_{i j}=\delta i j=0$ for all $i, j$ & {$[0.00]$} \\
\hline & No GARCH-M & $H_{0}: \psi_{i j}=$ for all $i, j$ & {$[0.00]$} \\
\hline & No Asymmetry & $H_{0}: \delta_{i j}=$ for all $i, j$ & {$[0.00]$} \\
\hline & Diagonal GARCH & $H_{0}: \alpha_{12}^{*}=\alpha_{21}^{*}=\beta_{12}^{*}=\beta_{21}^{*}=\delta_{12}^{*}=\delta_{21}^{*}=0$ & {$[0.00]$} \\
\hline \multirow[t]{5}{*}{ France } & Diagonal VARMA & $H_{0}: \Gamma_{12}^{i}=\Gamma_{21}^{i}=\theta_{12}^{i}=\theta_{21}^{i}=0$ & {$[0.00]$} \\
\hline & No GARCH & $H_{0}: \alpha_{i j}=\beta_{i j}=\delta i j=0$ for all $i, j$ & {$[0.00]$} \\
\hline & No GARCH-M & $H_{0}: \psi_{i j}=$ for all $i, j$ & {$[0.00]$} \\
\hline & No Asymmetry & $H_{0}: \delta_{i j}=$ for all $i, j$ & {$[0.00]$} \\
\hline & Diagonal GARCH & $H_{0}: \alpha_{12}^{*}=\alpha_{21}^{*}=\beta_{12}^{*}=\beta_{21}^{*}=\delta_{12}^{*}=\delta_{21}^{*}=0$ & {$[0.00]$} \\
\hline \multirow[t]{5}{*}{ Germany } & Diagonal VARMA & $H_{0}: \Gamma_{12}^{i}=\Gamma_{21}^{i}=\theta_{12}^{i}=\theta_{21}^{i}=0$ & {$[0.00]$} \\
\hline & No GARCH & $H_{0}: \alpha_{i j}=\beta_{i j}=\delta i j=0$ for all $i, j$ & {$[0.00]$} \\
\hline & No GARCH-M & $H_{0}: \psi_{i j}=$ for all $i, j$ & {$[0.00]$} \\
\hline & No Asymmetry & $H_{0}: \delta_{i j}=$ for all $i, j$ & {$[0.00]$} \\
\hline & Diagonal GARCH & $H_{0}: \alpha_{12}^{*}=\alpha_{21}^{*}=\beta_{12}^{*}=\beta_{21}^{*}=\delta_{12}^{*}=\delta_{21}^{*}=0$ & {$[0.09]$} \\
\hline \multirow[t]{5}{*}{ Italy } & Diagonal VARMA & $H_{0}: \Gamma_{12}^{i}=\Gamma_{21}^{i}=\theta_{12}^{i}=\theta_{21}^{i}=0$ & {$[0.00]$} \\
\hline & No GARCH & $H_{0}: \alpha_{i j}=\beta_{i j}=\delta i j=0$ for all $i, j$ & {$[0.00]$} \\
\hline & No GARCH-M & $H_{0}: \psi_{i j}=$ for all $i, j$ & {$[0.00]$} \\
\hline & No Asymmetry & $H_{0}: \delta_{i j}=$ for all $i, j$ & {$[0.00]$} \\
\hline & Diagonal GARCH & $H_{0}: \alpha_{12}^{*}=\alpha_{21}^{*}=\beta_{12}^{*}=\beta_{21}^{*}=\delta_{12}^{*}=\delta_{21}^{*}=0$ & {$[0.00]$} \\
\hline \multirow[t]{5}{*}{ Japan } & Diagonal VARMA & $H_{0}: \Gamma_{12}^{i}=\Gamma_{21}^{i}=\theta_{12}^{i}=\theta_{21}^{i}=0$ & {$[0.00]$} \\
\hline & No GARCH & $H_{0}: \alpha_{i j}=\beta_{i j}=\delta i j=0$ for all $i, j$ & {$[0.00]$} \\
\hline & No GARCH-M & $H_{0}: \psi_{i j}=$ for all $i, j$ & {$[0.00]$} \\
\hline & No Asymmetry & $H_{0}: \delta_{i j}=$ for all $i, j$ & {$[0.56]$} \\
\hline & Diagonal GARCH & $H_{0}: \alpha_{12}^{*}=\alpha_{21}^{*}=\beta_{12}^{*}=\beta_{21}^{*}=\delta_{12}^{*}=\delta_{21}^{*}=0$ & {$[0.00]$} \\
\hline \multirow[t]{5}{*}{ UK } & Diagonal VARMA & $H_{0}: \Gamma_{12}^{i}=\Gamma_{21}^{i}=\theta_{12}^{i}=\theta_{21}^{i}=0$ & {$[0.00]$} \\
\hline & No GARCH & $H_{0}: \alpha_{i j}=\beta_{i j}=\delta i j=0$ for all $i, j$ & {$[0.00]$} \\
\hline & No GARCH-M & $H_{0}: \psi_{i j}=$ for all $i, j$ & {$[0.00]$} \\
\hline & No Asymmetry & $H_{0}: \delta_{i j}=$ for all $i, j$ & {$[0.00]$} \\
\hline & Diagonal GARCH & $H_{0}: \alpha_{12}^{*}=\alpha_{21}^{*}=\beta_{12}^{*}=\beta_{21}^{*}=\delta_{12}^{*}=\delta_{21}^{*}=0$ & {$[0.00]$} \\
\hline
\end{tabular}


Table 4: The Values of the $\Psi$ Matrix for the remainder of the G7

\begin{tabular}{ccccccc}
\hline \hline & UK & Germany & France & Italy & Canada & Japan \\
\hline$\Psi_{11}$ & 0.58 & 0.54 & -0.05 & -0.18 & 0.02 & 0.19 \\
& $(0.01)$ & $(0.13)$ & $(0.01)$ & $(0.03)$ & $(0.00)$ & $(0.48)$ \\
$\Psi_{12}$ & -0.53 & 0.14 & 0.74 & 3.93 & 0.03 & 0.54 \\
& $(0.03)$ & $(0.37)$ & $(0.07)$ & $(0.16)$ & $(0.00)$ & $(2.33)$ \\
$\Psi_{21}$ & 0.40 & -0.01 & 0.02 & -0.01 & -0.03 & 0.32 \\
& $(0.04)$ & $(0.01)$ & $(0.00)$ & $(0.00)$ & $(0.00)$ & $(0.12)$ \\
$\Psi_{22}$ & 0.05 & 0.30 & 0.82 & 0.06 & 0.00 & 1.48 \\
& $(0.06)$ & $(0.10)$ & $(0.04)$ & $(0.01)$ & $(0.00)$ & $(1.98)$ \\
\hline \hline
\end{tabular}

Notes: The numbers in brackets are standard errors. 